08,09

\title{
Тушение люминесценции в керамиках оксида алюминия допированных магнием
}

\author{
(C) С.В. Звонарев, Н.О. Смирнов \\ Уральский федеральный университет, \\ Екатеринбург, Россия \\ E-mail: s.v.zvonarev@urfu.ru
}

\begin{abstract}
Методами импульсной катодо-, фото и термолюминесценции исследовано влияние примеси магния на люминесцентные свойства керамики оксида алюминия, спеченной при высоких температурах в вакууме. При концетрациях допанта более $1 \mathrm{wt} . \%$ высокотемпературный синтез приводит к созданию дефектов, ассоциированных с магнием и идентифицированных на спектрах импульсной катодолюминесценции $(520 \mathrm{~nm})$ и фотолюминесценции $(767 \mathrm{~nm})$, а также кривых термолюминесценции $(380 \mathrm{~K})$. Установлено, что увеличение концентрации магния приводит к тушению люминесценции: собственных центров оксида алюминия $\left(F\right.$-центров) в полосе эмиссии ИКЛ $400 \mathrm{~nm}$, примесных дефектов $\left(\mathrm{Mn}^{4+}\right.$ и $\left.\mathrm{Cr}^{3+}\right)$ в полосах эмиссии ФЛ 673 и $689 \mathrm{~nm}$, всех регистрируемых пиков термолюминесценции при $380,450,615 \mathrm{~K}$.
\end{abstract}

Исследование выполнено за счет гранта Российского научного фонда (проект № 18-72-10082).

DOI: 10.21883/FTT.2019.05.47596.36F

\section{1. Введение}

Люминесцентные свойства материалов активно исследуются с целью создания на их основе высокоэффективных люминофоров. Среди них несомненный интерес вызывают оксидные системы, применяемые в различных областях науки и техники [1-3]. Оксид алюминия в монокристаллическом и наноструктурном состоянии используется в настоящее время как детектор для люминесцентной дозиметрии ионизирующих излучений [4-5]. Люминесцентные свойства данного материала зависят от его структурного состояния и механизмов переноса заряда. Особый интерес представляет изучение таких процессов при наличии в материале различных дефектов, способных захватывать свободные носители заряда [6]. Изменение состояния их заселенности приводит к перераспределению вероятностей конкурирующих процессов переноса электронов и дырок между дефектными центрами и делокализованными зонами, и, следовательно, к изменению люминесцентных свойств материала. Экспериментальное исследование оптических свойств подобных дефектных материалов представляет значительный интерес для понимания особенностей структурного состояния и прогнозирования свойств новых функциональных материалов.

Изменение люминесцентных свойств происходит за счет создания примесных дефектов при допировании исходной матрицы оксида алюминия различными ионами переходных металлов, например, хромом [7], марганцем [8], магнием и титаном [9]. В качестве исходной оксидной матрицы наиболее часто используется оксид алюминия. Высокая интенсивность люминесценции при определенной длине волны в подобном материале также может достигаться за счет использования в качестве примесей таких редкоземельных элементов как европий [10], эрбий [11], неодим [12] и тербий [13]. В бинар- ных и многокомпонентных оксидах, в том числе в оксиде алюминия, ключевую роль играют дефекты структуры материала, в частности кислородные вакансии и примесные центры [14-15].

Магний во многих случаях применяется в качестве примеси исходной матрицы оксида алюминия при создании анионо-дефектной структуры $[16,17]$. В последнее время в качестве исходной матрицы для перспективного использования в оптике исследуется шпинель алюмината магния с различными примесями [18-20]. При этом особое внимание уделяется индуцированным дефектам, способствующим возникновению люминесценции в подобных керамиках [21]. В большей степени интенсивность собственных полос люминесценции матрицы, примесных центров, а также возможно новых агрегатных и кластерных центров должна зависеть от концентрации примеси и связанных с ней механизмов концентрационного тушения и конкурирующих эффектов. В этой связи целью данной работы является исследование люминесцентных свойств керамики на основе оксида алюминия с магнием в зависимости от концентрации примеси методами импульсной катодо- (ИКЛ), фото- (ФЛ) и термолюминесценции (ТЛ).

\section{2. Материалы и методы}

Керамики оксида алюминия, допированные магнием, получены путем высокотемпературного отжига компактов, предварительно пропитанных в растворе нитрата примеси. Спекание керамик выполнено в вакууме при давлении $0.013 \mathrm{~Pa}$ в высокотемпературной вакуумной электропечи СНВЭ 9/18 при варьировании температуры от 1500 до $1700^{\circ} \mathrm{C}$ в течение двух h. Допирование проводилось путем пропитки исходного компакта в растворе нитрата магния при варьировании концентрации 
примеси в растворе от 0.01 до $6.85 \mathrm{wt} . \%$. Максимальное значение концентрации примеси было ограничено получением насыщенного раствора соли при комнатной температуре в рамках выбранного метода допирования. Длительность пропитки была выбрана равной $1 \mathrm{~h}$, при которой обеспечивалось равномерное распределение примеси по всему объему образца. Исходные компакты были получены методом холодного статического прессования порошка $\alpha-\mathrm{Al}_{2} \mathrm{O}_{3}$ на гидравлическом прессе ПРГ-1-50 при давлении $0.7 \mathrm{GPa}$. Коммерческий нанопорошок с размером частиц 10-150 $\mathrm{nm}$ синтезирован алкоголятным методом. С целью повышения механической прочности перед процессом пропитки образцы отжигались при температуре $450^{\circ} \mathrm{C}$ в течение двух h. Для создания группы образцов керамик с большей концентрацией собственных дефектов часть образцов были термохимически окрашены при спекании в вакууме в присутствии углерода при использовании высокочистых графитовых стержней $(20 \mathrm{~g})$. Углерод является хорошей восстановительной средой и способствует получению кислородо-дефицитных образцов керамики. Более подробно метод подготовки образцов описан в [22].

Экспериментальное исследование переноса заряда и влияния нестехиометрии на люминесцентные свойства полученных керамик, обусловленных присутствием дефектов и примесных центров, выполнено с помощью совокупности экспериментальных методов импульсной катодо-, фото- и термолюминесценции. Регистрация спектров катодолюминесценции осуществлялась спектрометром „КЛАВИ“, имеющего следующие технические характеристики: длительность пучка $2 \mathrm{~ns}$, средняя энергия электронов $130 \pm 10 \mathrm{keV}$ при плотности тока $60 \mathrm{~A} / \mathrm{cm}^{2}$, частота импульсов $1 \mathrm{~Hz}$, спектральный диапазон 350-750 nm. Измерения фотолюминесценции были проведены на спектрометре LS-55 фирмы Perkin Elmer c пульсирующей ксеноновой лампой в качестве источника света в диапазоне возбуждения 200-515 nm и эмиссии 430-900 nm. Измерения проводили в режиме фосфоресценции при задержке $0.02 \mathrm{~ms}$. Регистрация спектров в режиме флуоресценции вследствие интенсивного свечения образца не представлялась возможным. Измерение ТЛ выполнено на опытном образце дозиметрической системы „Грей“ при линейном нагреве в диапазоне температур от 300 до $670 \mathrm{~K}$ со скоростью $2 \mathrm{~K} / \mathrm{s}$ с использованием фотоумножителя HAMAMATSU Photonics (Япония) Н10722. Для возбуждения ТЛ использована электронная пушка с импульсным пучком дозой $1.5 \mathrm{kGy}$ за один импульс.

\section{3. Результаты и обсуждение}

Высокотемпературный синтез керамик оксида алюминия, допированных магнием, приводит к созданию как собственных дефектов матрицы, так и примесных центров (рис. 1). Полоса эмиссии с максимумом при $400 \mathrm{~nm}$ соответствует люминесценции $F$-центра оксида алюми-

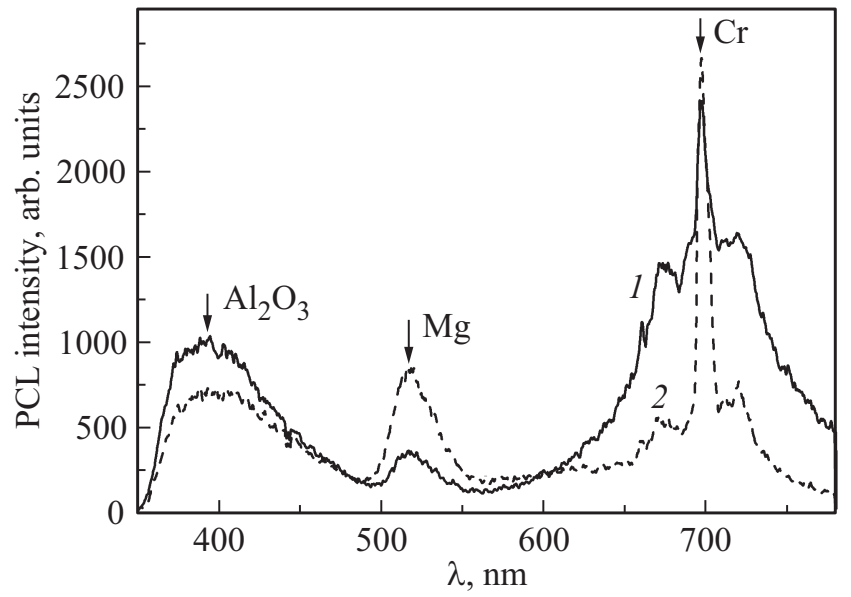

Рис. 1. Спектры ИКЛ керамики $\mathrm{Al}_{2} \mathrm{O}_{3}: \mathrm{Mg}$, отожженной при температуре $1500^{\circ} \mathrm{C}$ в вакууме: 1 - при наличии углерода, 2 - при отсутствии углерода.

ния [14]. Данный центр представляет собой вакансию кислорода с захваченными на нее двумя электронами. Наиболее интенсивная полоса на спектре ИКЛ связана c $R$-линией хрома $(693 \mathrm{~nm})$ [23], который мог присутствовать в исходном порошке в малых концентрациях. При высоких концентрациях ионов магния наблюдается полоса эмиссии с максимумом при $520 \mathrm{~nm}$, соответствующая агрегатному центру $F_{2}^{2+}(2 \mathrm{Mg})$, созданному в процессе синтеза [24]. В ряде работ данную полосу ассоциируют с агрегатными $F_{2}$-центрами, созданными кислородными вакансиями и центрами, образованными ионами алюминия [21]. Из литературы известно [25], что спекание при высоких температурах в присутствии углерода способствует созданию $F$-центров. Углерод при температуре спекания выше $1500^{\circ} \mathrm{C}$ превращается в газ и, являясь химически активным, вступает в реакцию с кислородом исходной матрицы оксида алюминия. В результате чего образуется нестехиометрия по кислороду и керамика становится кислородо-дефицитной. Указанная закономерность подтверждается у исследуемых керамик. Интенсивность полосы люминесценции при $400 \mathrm{~nm}$ выше для образцов, спеченных при наличии углерода. При этом следует заметить, что интенсивность полосы эмиссии при $520 \mathrm{~nm}$ уменьшается. В этой связи можно предположить, что основной вклад в люминесценцию полосы при $520 \mathrm{~nm}$ вносят не агрегатные центры, созданные кислородными вакансиями, а именно примесные центры магния.

Как было показано в предыдущих работах [26], для беспримесной керамики увеличение температуры отжига приводит к росту концентрации $F$-центров. Для керамики оксида алюминия с примесью магния наблюдается подобный эффект. Так интенсивность люминесценции в полосе $400 \mathrm{~nm}$ для керамик, отожженных при температуре $1700^{\circ} \mathrm{C}$ (рис. 2, кривая 3), превышает аналогичную величину для керамики, спеченной при температуре $1500^{\circ} \mathrm{C}$ (рис. 1, кривая 2) почти в 1.5 ра- 


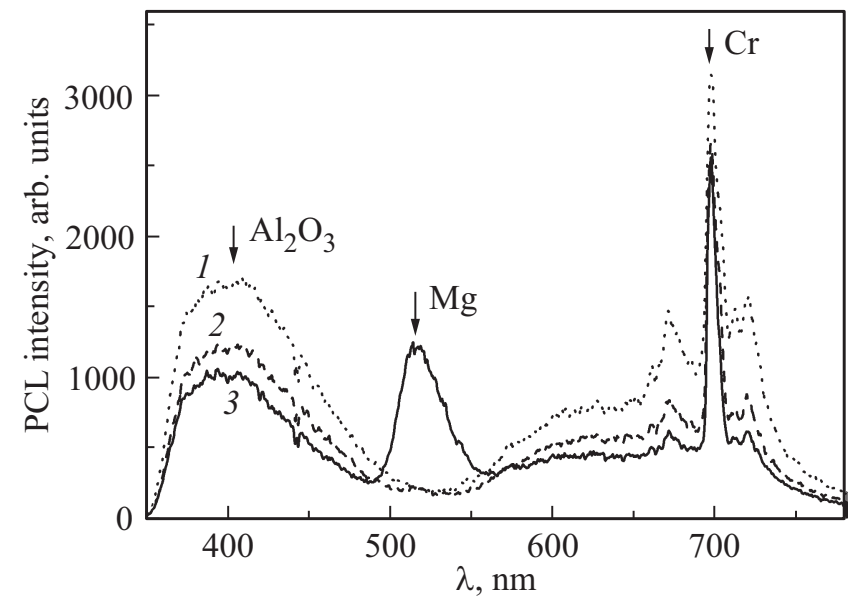

Рис. 2. Спектры ИКЛ керамик $\mathrm{Al}_{2} \mathrm{O}_{3}: \mathrm{Mg}$, спеченных при температуре $1700^{\circ} \mathrm{C}$, при различной концентрации: $1-0.1 \mathrm{wt} . \%$, $2-1$ wt. $\%, 3-6.85$ wt. $\%$.

за. Увеличение температуры отжига также приводит к росту интенсивности люминесценции в полосе $520 \mathrm{~nm}$. При высокой температуре формируется большее число примесных центров за счет замещения ионов алюминия магнием, а также встраиванием ионов магния в междоузлие, тем самым образуя магниевую шпинель. При низких концентрациях примеси подобный эффект не наблюдается. На рис. 2 представлены спектры ИКЛ керамики $\mathrm{Al}_{2} \mathrm{O}_{3}: \mathrm{Mg}$, спеченной при температуре $1700^{\circ} \mathrm{C}$ в течении двух часов, при варьировании концентрации допанта. Установлено, что полоса эмиссии при $520 \mathrm{~nm}$ регистрируется только при максимальном значении примеси в керамике. При этом рост концентрации магния приводит к тушению люминесценции в полосе эмиссии $F$-центра.

В спектре возбуждения ФЛ керамики $\mathrm{Al}_{2} \mathrm{O}_{3}: \mathrm{Mg}$ присутствуют три наиболее интенсивные полосы с максимумами при 290, 315 и $420 \mathrm{~nm}$ (рис. 3, a). Возбуждение в полосу $290 \mathrm{~nm}$ приводит к эмиссии при $767 \mathrm{~nm}$. Полоса эмиссии с максимумом $673 \mathrm{~nm}$ доминирует при возбуждении в полосу $315 \mathrm{~nm}$, а эмиссия при $689 \mathrm{~nm}$ - при возбуждении в полосу $420 \mathrm{~nm}$ соответственно. Полосы эмиссии в диапазонах 674-678, 692-694 и 777-779 nm связывают с примесными дефектами $\mathrm{Mn}^{4+}(R$-линия), $\mathrm{Cr}^{3+}\left(R\right.$-линия) и $\mathrm{Ti}^{3+}$, соответственно, которые всегда присутствуют в оксиде алюминия [15]. Первые две полосы эмиссии соответствуют переходам ${ }^{2} E \rightarrow{ }^{4} A_{2}$, а третья переходу ${ }^{2} E \rightarrow{ }^{2} T_{2}$. Люминесценция в полосах 693 и $676 \mathrm{~nm}$ регистрировалась для исследуемой керамики на спектрах ИКЛ. Полоса эмиссии с максимумом при $767 \mathrm{~nm}$ на спектре ИКЛ не наблюдалась. При этом следует заметить, что уменьшение концентрации примеси приводит к снижению интенсивности данной полосы. При концентрации примеси 1 wt.\% данная полоса на спектре ФЛ не регистрируется. Заметим, что возбуждение данной полосы происходит при $4.15 \mathrm{eV}$, что соответствует возбуждению агрегатных $F_{2}^{2+}$ или примесных центров катионов $\mathrm{Mg}^{2+}$. В отличие от полосы $767 \mathrm{~nm}$, интенсивность эмиссии при 673 и $689 \mathrm{~nm}$ уменьшается с ростом концентрации магния. При этом тушение люминесценции полосы $673 \mathrm{~nm}$ является более существенным в сравнении с полосой $689 \mathrm{~nm}$. Так при
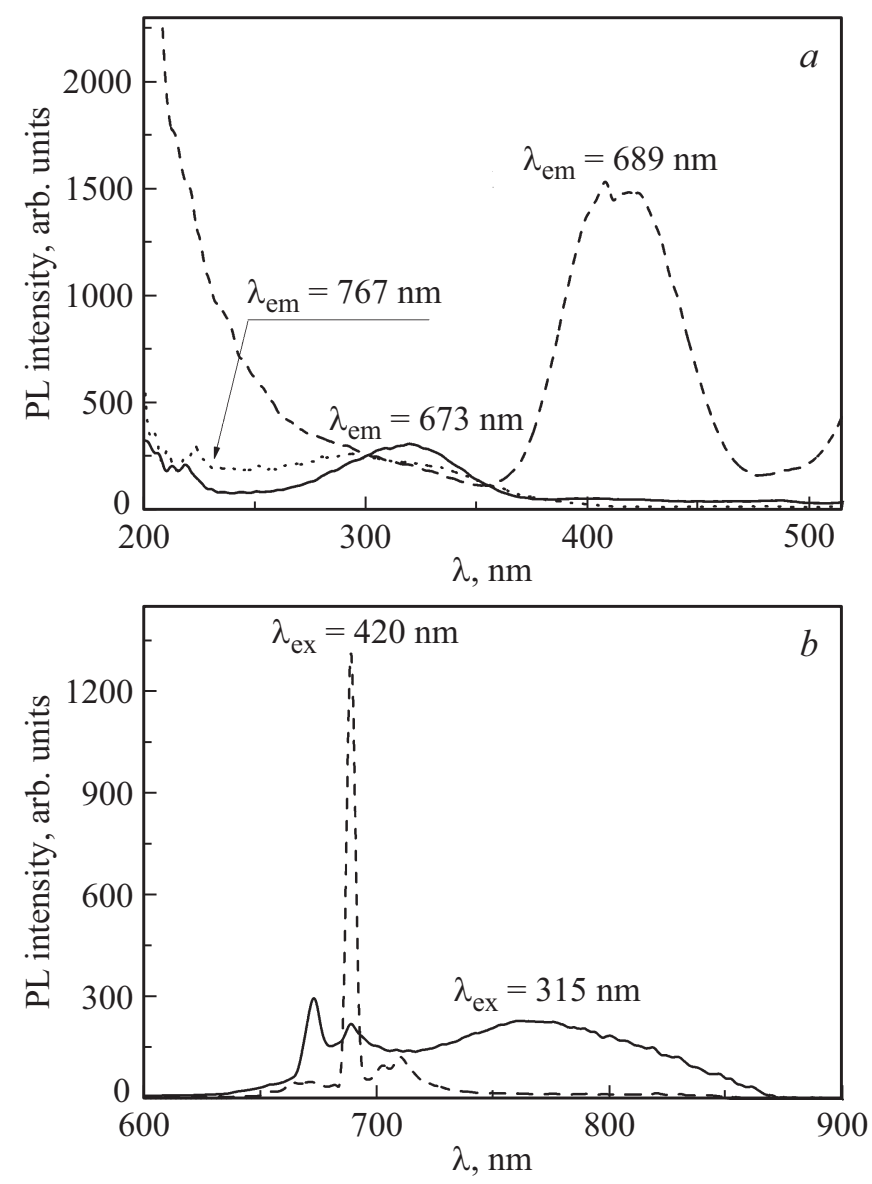

Рис. 3. Спектры возбуждения $(a)$ и эмиссии $(b)$ ФЛ исследуемой керамики с концентрацией магния $6.85 \mathrm{wt} . \%$, спеченной при температуре $1700^{\circ} \mathrm{C}$.

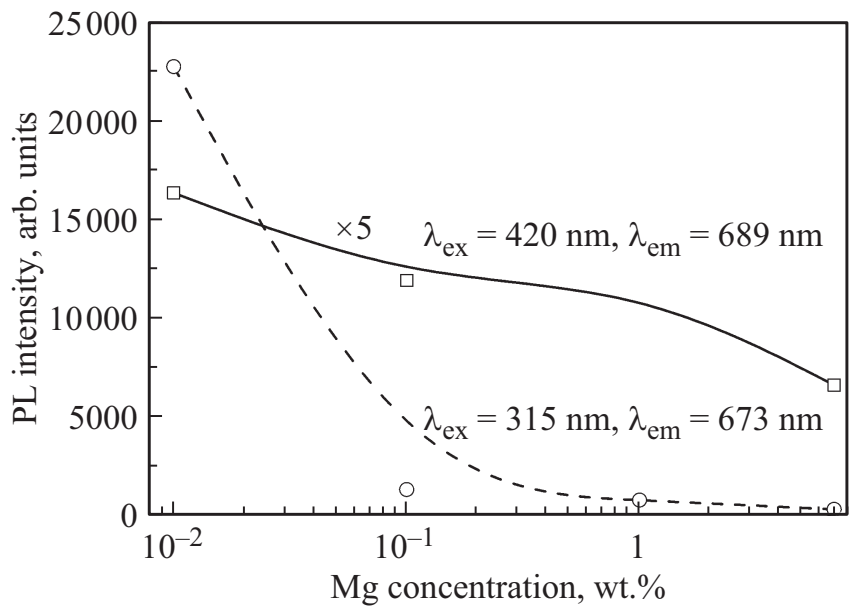

Рис. 4. Зависимость интенсивности ФЛ от концентрации допанта для различных полос эмиссии и возбуждения 
увеличении концентрации допанта почти на 3 порядка с 0.01 до 6.85 wt.\% снижение интенсивности в полосе $689 \mathrm{~nm}$ происходит в 2.5 раза, а в полосе $673 \mathrm{~nm}$ - более чем в 100 раз (рис. 4).
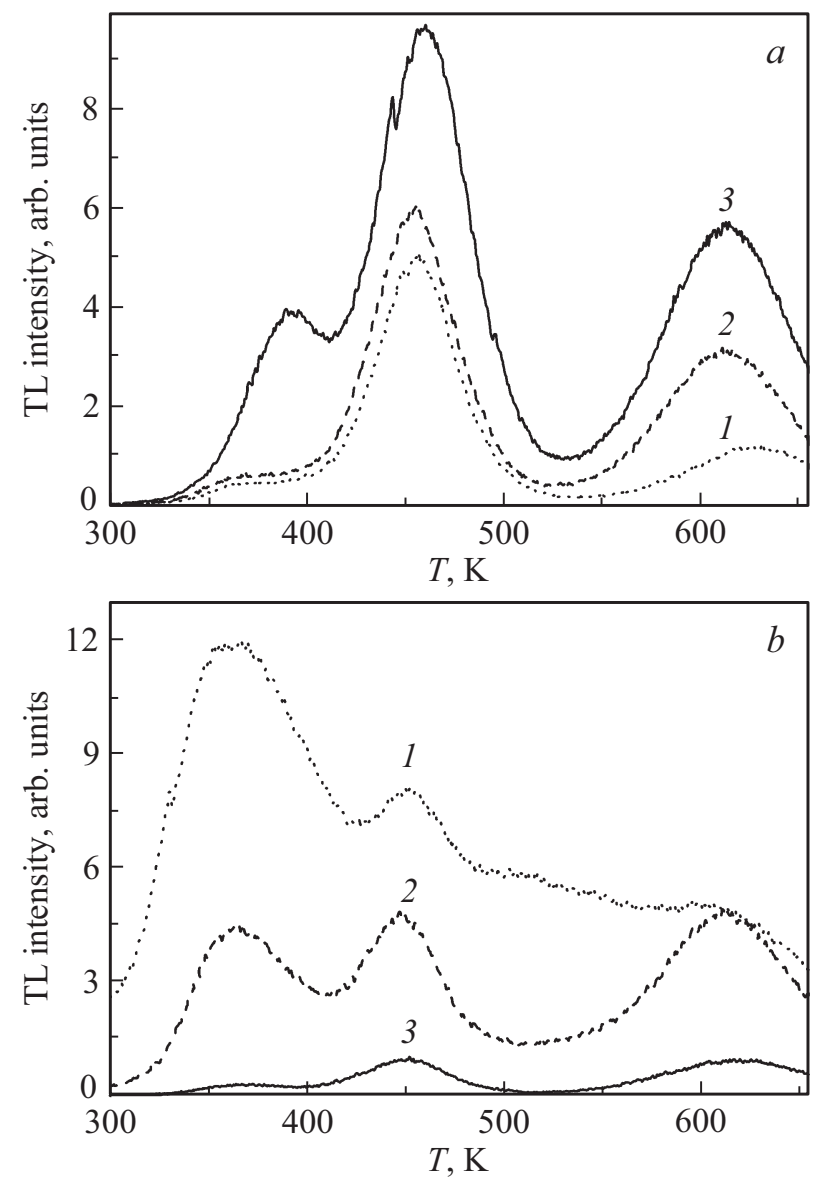

Рис. 5. Кривые ТЛ исследуемых керамик с концентрацией магния $0.01 \mathrm{wt} . \%(a)$ и $6.85 \mathrm{wt.} \%(b)$ при варьировании температуры спекания: $1-1500^{\circ} \mathrm{C}, 2-1600^{\circ} \mathrm{C}, 3-1700^{\circ} \mathrm{C}$.

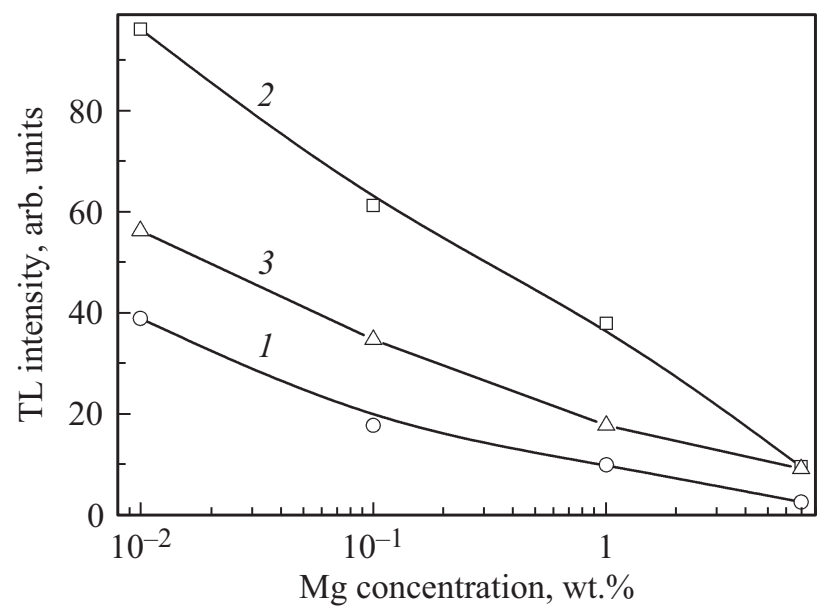

Рис. 6. Зависимость интенсивности ТЛ от концентрации допанта для различных пиков ТЛ: $1-380 \mathrm{~K}, 2-450 \mathrm{~K}$, $3-615 \mathrm{~K}$.
На рис. 5 показаны кривые ТЛ исследуемых керамик, спеченных при различных температурах, для концентраций магния 0.01 и 6.85 wt.\%. Для обеих концентраций на графиках можно выделить 3 пика с максимумами при 380,460 и $615 \mathrm{~K}$. Из литературы известно [27], что люминесценция собственных центров оксида алюминия регистрируется в диапазоне $450-470 \mathrm{~K}$, а примесных центров хрома - в диапазоне 620-640 K. При этом температура отжига для разных концентраций допанта оказывает различное влияние на интенсивность ТЛ для всех регистрируемых пиков. Так для концентрации 0.01 wt.\% увеличение температуры спекания приводит к росту интенсивности люминесценции, а наиболее интенсивным пиком является пик собственных центров свечения керамики оксида алюминия при $460 \mathrm{~K}$. При высокой концентрации магния $(6.85 \mathrm{wt} . \%)$ рост температуры отжига оказывает негативное воздействие на интенсивность, и наблюдается тушение люминесценции. Доминирующим пиком при данной концентрации для температуры отжига $1500^{\circ} \mathrm{C}$ является пик при $380 \mathrm{~K}$, при температуре $1600^{\circ} \mathrm{C}$ все пики ТЛ сравнимы по своей интенсивности, а при $1700^{\circ} \mathrm{C}$ наиболее интенсивными являются высокотемпературные пики. В этой связи низкотемпературный пик при $380 \mathrm{~K}$ может быть связан как с примесью магния, так и с более сложными центрами, созданными в исследуемой керамике.

При увеличении концентрации ионов магния на кривых ТЛ, также как и на спектрах ИКЛ наблюдается тушение люминесценции собственных центров оксида алюминия и примесных центров хрома (рис. 6). При этом увеличение концентрации ионов магния приводит к росту интенсивности ИКЛ в полосе $520 \mathrm{~nm}$ и снижению интенсивности ТЛ в пике 390 К. Данный факт может как раз определять сложное структурное состояние данного дефекта.

\section{4. Заключение}

Таким образом, ИКЛ- и ФЛ-спектры, а также ТЛ кривые были измерены для оценки влияния концентрации ионов магния на люминесцентную как собственных центров керамики оксида алюминия, так и примесных центров, созданных в результате высокотемпературного спекания в вакууме. Наличие сильно восстановительной среды при отжиге приводит к созданию меньшей концентрации примесных центров магния. Показано, что увеличение концентрации ионов магния приводит к тушению основной полосы люминесценции оксида алюминия ( $F$-центров). При этом полоса эмиссии при $520 \mathrm{~nm}$ регистрируется при концетрациях допанта более $1 \mathrm{wt} . \%$ и ее интенсивность растет с увеличение концентрации. Аналогичный эффект наблюдается при анализе ФЛ спектров. Полоса эмиссии при $767 \mathrm{~nm}$ обнаруживается только при высоких концентрациях магния, для всех остальных полос эмиссии в спектре регистрируется тушение люминесценции с ростом концентрации магния. 
На кривых ТЛ выделяются три пика люминесценции с максимумами при 380,460 и $615 \mathrm{~K}$, интенсивность которых с ростом концентрации ионов магния уменьшается.

\section{Список литературы}

[1] S.P. Feofilov, A.B. Kulinkin, A.K. Kaveev, N.S. Sokolov, S.M. Suturin. Opt. Mater. 83, 43 (2018).

[2] И.Н. Огородников, М.Д. Петренко, В.Ю. Иванов. ФТТ 60, 132 (2018)

[3] K.W. Park, H.S. Lim, S.W. Park, G. Deressa, J.S. Kim. Chem. Phys. Lett. 636, 141 (2015).

[4] С.В. Никифоров, В.С. Кортов. ФТТ 59, 1695 (2017).

[5] M. Oja, E. Tõldsepp, E. Feldbach, H. Mägi, S. Omelkov, M. Kirm. Rad. Meas. 90, 75 (2016).

[6] С.В. Горбунов, А.Ф. Зацепин, В.А. Пустоваров, С.О. Чолах, В.Ю. Яковлев. ФТТ 47, 708 (2005).

[7] D. Liu. Ceram. Int. 39, 4765 (2013).

[8] I.V. Gasenkova, N.I. Mukhurov, S.P. Zhvavyi, E.E. Kolesnik, A.P. Stupak. J. Lumin. 185, 298 (2017).

[9] Q. Liu, Q. Yang, G. Zhao, S. Lu. J. Alloy. Compd. 582, 754 (2014).

[10] N. Rakov, G.S. Maciel. J. Lumin. 127, 703 (2007).

[11] K. Drdlíková, R. Klement, D. Drdláka, T. Spusta, D. Galusekb, K. Maca. J. Eur. Ceram. Soc. 37, 2695 (2017).

[12] Y. Gui, Q. Yang, Y. Shao, Y. Yuan. J. Lumin. 184, 232 (2017).

[13] E.H. Penilla, Y. Kodera, J.E. Garay. Adv. Funct. Mater. 23, 6036 (2013).

[14] B.D. Evans, G.J. Pogatshnik, Y. Chen. Nucl. Instrum. Meth. Phys. Res. B 91, 258 (1994).

[15] A.I. Kostyukov, A.V. Zhuzhgov, V.V. Kaichev, A.A. Rastorguev, V.N. Snytnikov, V.N. Snytnikov. Opt. Mater. 75, 757 (2018).

[16] N.M. Trindade, L.G. Jacobsohn. J. Lumin. 204, 598 (2018).

[17] J.M. Kalita, M.L. Chithambo. J. Lumin. 182, 177 (2017).

[18] D. Valiev, O. Khasanov, E. Dvilis, S. Stepanov, E. Polisadova, V. Paygin. Ceram. Int. 44, 20768 (2018).

[19] M.G. Brik, J. Papan, D.J. Jovanović, M.D. Dramićanin. J. Lumin. 177, 145 (2016).

[20] B.S. Choi, O.G. Jeong, J.C. Park, J.W. Kim, S.J. Lee, J.H. Ryu, J.I. Lee, H. Cho. J. Ceram. Proc. Res. 17, 778 (2016).

[21] S.S. Raj, S.K. Gupta, V. Grover, K.P. Muthe, V. Natarajan, A.K. Tyagi. J. Mol. Struct. 1089, 81 (2015).

[22] S.V. Zvonarev, V.S. Kortov, A.V. Chikin, P.P. Sannikov. In: Physics, Technologies and Innovation (PTI-2016). AIP Conf. Proc. 1767 / Ed. V.A. Volkovich. American Institute of Physics, Melville, N. Y. (2016) C. 020025.

[23] А.Б. Кулинкин, С.П. Феофилов, Р.И. Захарченя. ФТТ 42, 835 (2000).

[24] S. Sanyal, M.S. Akselrod. J. Appl. Phys. 98, 033518 (2005).

[25] V. Kortov, A. Kiryakov, S. Nikiforov, D. Ananchenko, S. Zvonarev. Vacuum 143, 433 (2017).

[26] V. Kortov, S. Zvonarev, A. Kiryakov, D. Ananchenko. Mater. Chem. Phys. 170, 168 (2016).

[27] M.S. Akselrod, V.S. Kortov, D.I. Kravetsky, V.I. Gotlib. Rad. Prot. Dos. 32, 15 (1990).

Редактор Т.Н. Василевская 